Eye on Psi Chi: Summer 2009

\title{
Organizing Your Personal Statement: An Outline to Get You Started
}

by Merry J . Sleigh, PhD - Winthrop University (SC)

Category: Graduate School

One of the biggest challenges when applying to graduate school is writing the personal statement, particularly given that the personal statement is one of the most important criteria for graduate admission (Norcross, Kohout, \& Wicherski, 2006). Applicants have a restricted amount of space to describe their past accomplishments, future plans, and interest in a particular graduate program. Despite impressive credentials and experiences, students often don't know how to get started. As suggested below, getting started can begin with organizing the information that needs to go into your personal statement.

\section{Opening Paragraph: 4-6 sentences}

The selection committee will read many personal statements each year, and the majority of these statements start in a similar fashion. Students tend to describe themselves in terms of their academic work, high level of motivation, or desire to help others. Because these characteristics are common among applicants, they will not distinguish you as an individual. I must admit that when I had the opportunity to review graduate applicants, it was challenging to remember which details of the many applications went with which individual.

Think of the opening paragraph as an opportunity for you to paint a "mental picture" of yourself for your readers. Identify something about you or your experiences that make you unique and well-suited for graduate training - a fact that illustrates the type of person you are. Incorporate this element into the opening paragraph. Your goal is for the committee to be interested enough in the information to retain it and use it as a central point around which to organize the other details in your packet and to help them remember you. For example, you might have traveled extensively, been raised in a foster home, led a service project in your community, paid for your own college education, overcome a physical challenge, survived a great loss, or double-majored. Be thoughtful about the mental picture that you choose; you do not want to invoke pity, raise a red flag, or create a complicated self-portrait. Keep the paragraph short and focused, four to six sentences in length. The point is to help the selection committee see you as a person, not just another folder.

TIPS 
- Keep this section short and organized. Your goal is to briefly introduce yourself.

- You have a limited amount of space, so avoid stating ideas that your readers already know (e.g., "I love learning about psychology" or "I want to get a graduate degree in psychology so that I can continue to learn about why people do the things they do"). Your application to a psychology graduate program is evidence that you enjoy the field of psychology and would like to obtain a graduate degree.

- Don't begin your statement with a quotation unless it is impossible to express the idea better.

- First impressions matter, so take the time to create a strong opening. Good writing is a process, requiring feedback and multiple drafts.

- You might choose to write this section last. Put together the rest of the paper, and then think about the overall image you would like to present to introduce yourself and the upcoming credentials.

- Read Osborne (1996), and Appleby and Appleby (2007) for advice about how to appropriately incorporate personal information into your statement.

\section{Academic Accomplishments: 5-7 sentences}

You might choose to have a second paragraph that emphasizes aspects of your academic work. Many students make the mistake of repeating information that can be found elsewhere in the application. Remember, the selection committee will have your transcript, GPA, and GRE score. You do not need to repeat this information unless repeating it serves a purpose. For example, if you want to address why your GRE score does not represent your ability or how your grades dramatically improved after your first year, this paragraph might be the ideal place to do so. Otherwise, use this paragraph to expand on, or supplement, the information you have already provided.

As you write about the work you have done in college, link the activities to skills and qualities that you possess. Avoid simply listing activities you have done or classes you have taken. Such lists do not tell the reader much beyond the fact that you stayed busy. Similarly, don't list a series of adjectives that you feel describe you. Instead, offer evidence that leads the reader to conclude that those adjectives fit you. For example, you could explain that you intentionally selected challenging coursework because you are willing to work hard and are motivated to learn. You might reveal that you worked full-time while maintaining a high GPA to show that you have good time management skills and the ability to multi-task. This presentation is more effective than simply writing something like, "I am willing to work hard, am motivated to learn, and have good time management skills."

\section{TIPS}

- Share your accomplishments honestly, but maintain a humble tone. You may be competing against other applicants who have a higher GPA or stronger GRE scores than you.

- Quantify your accomplishments when possible. For example, provide your class rank (e.g., 15 out of 475; top 10\%) rather than making vague statements such as "high GPA" or "top student." 
- Feel free to share activities not directly related to your field, especially if they reveal positive aspects of who you are. • Be specific. "I helped our Psi Chi officers organize a book drive for a local children's shelter" is more informative than "I was an active member of Psi Chi."

- See Appleby (2003) for an examination of transcript features that may need to be addressed in a personal statement.

- Start concentrating on writing smooth transition sentences to start each paragraph. Show the reader how this paragraph logically follows the preceding one. Your reader should understand your overall organization as well as the main idea of each paragraph.

\section{Research Experience: 5-8 sentences}

Most graduate programs include a research component and research experience as an important factor in admission decisions (Collins, 2001; Norcross, et al., 2006). Thus, documenting your research experiences can be a critical aspect of your application. The term "research experience" can include a range of participation from entering data to publishing independent work. You need to be specific about the research skills you have acquired. "I worked in a child development lab during my senior year" needs additional details such as, "I was responsible for greeting parents, explaining informed consent, and videotaping parent-baby conversations." Graduate programs appreciate students who understand and are prepared for research training-from the mundane to the more challenging aspects. Thus, even limited exposure to research may be useful to include in this paragraph.

You also can use this paragraph to share your other relevant characteristics. For example, let the reader know if you took the initiative to create a research opportunity or were given additional laboratory responsibilities as a result of your efforts. Make sure to quantify the length and/or level of participation. Working in a laboratory for three semesters reveals a higher level of commitment and perseverance than one semester of effort. As you focus on your research experience, make sure to share credit where it is due. Your selection committee includes faculty who will serve as research mentors for incoming students and will appreciate a student who respects the lab team and faculty advisor.

\section{TIPS}

- Keep in mind that you will be conveying your attitude toward research alongside your research experiences. Be thoughtful about the attitude you want to express (e.g., Do you work well independently? Are you a strong team player?).

- Your research experience does not have to directly relate to your field of interest in graduate school, as many research skills are transferable.

- Don't forget to include research-related activities, such as applying for grants, receiving travel funding for a conference, or being nominated for an award.

\section{Employment/Volunteer Work/Clinical Experience: 5-8 sentences}


Graduate programs invest a great deal of time and money in their students; therefore, selection committees want to choose students who are knowledgeable about and prepared for training. Each program might place its training emphasis in a slightly different area. You need to think about each program to which you are applying and identify the qualities that are desired by that program. For example, if you are applying to an industrial/organizational program, the school is likely to be interested in any statistical skills, legal training, or management experience you have. If you are applying to a clinical program, the school will want applicants who understand issues such as confidentiality, professional boundaries, and mirroring. Being able to identify these qualities demonstrates to the program that you are knowledgeable about the training they provide.

After you have identified the qualities desired by your program, carefully consider how your work, either paid or volunteer, has helped you develop these skills and an awareness of the issues related to your field of interest (see Appleby, Keenan, \& Mauer, 1999, for a list of characteristics valued by graduate programs). You may not have direct experience in your field of interest, so think broadly about how the work you have done translates to graduate training. Perhaps you held a position which required you to do public speaking; those speeches may have helped you develop an awareness of your audience, an ability to communicate complex ideas in an accessible fashion, develop rapport with a diverse group of people, project a professional demeanor, or showcase technological savvy. Write about the aspects that are most relevant to the degree you are seeking. When possible, clarify to the selection committee how your capabilities will benefit you and your program during graduate training.

Graduate committees recognize that the skills you can acquire as an undergraduate are limited, so don't exaggerate what you have done. The committee is looking for students who have a good foundation on which to build during graduate school. They are not seeking applicants who believe they have already mastered the necessary skills. Instead of phrasing an idea as "Because of my exceptional people skills, I was asked to do intake interviews for new clients," you might want to use, "Handling the intake interviews for new clients challenged me to build rapport with a variety of personalities and strengthened my time management skills." Show humility and a willingness to learn.

\section{TIPS}

- Avoid using local abbreviations or jargon that will be unfamiliar to your committee. Use the full name of places where you have worked or positions you have held (e.g., Mount Holly Juvenile Detention and Attention Center vs. Attention Center; Resident Counselor vs. R.C.).

- Look for overall strengths as well as specific skills. If you are involved in a wide range of activities, emphasize the breadth of your experiences. If you have devoted yourself to a particular cause, emphasize depth and commitment. 
- Read Landrum (2002) for a variety of activities that prepare students for graduate training and Khemlani (2008) for suggestions about how to consider your personal statement from the perspective of your readers.

\section{Future Plans/Goodness-of-Fit: 6-9 sentences}

Typically, graduate programs will ask you to state your future plans. This paragraph allows you to describe your goals and explain how you are a good fit for a particular graduate program. In order to explain fit, you need to investigate each program to which you are applying. If you have done your homework, then you will have picked each program because it has characteristics that appeal to you. Show the selection committee that you are familiar with these characteristics, and that these characteristics are a good match with your career goals. Selection committees will not be impressed with over-the-top flattery that praises features that apply to most graduate programs (e.g., "I would love to learn from your very accomplished faculty"). Instead, consider unique elements that attracted you to that specific program. Perhaps the location of the program will afford you a professional experience that you would not get otherwise. Perhaps the program's heavy focus on practical experience matches your future goals. Perhaps your interests match the program's specialization. Reveal your familiarity with the program and closely tie those facts to your career goals. You want to explain how the program meets your training needs and how you are a good fit for the structure of that specific program.

Some schools will ask you to mention specific faculty members whose expertise matches your current interests. If asked, a good rule of thumb is to mention two or three faculty members with similar research programs. Demonstrate that you are familiar with their expertise while avoiding excessive name-dropping or flattery. "My current interests match most closely with Dr. Susan Doe's work with fetal alcohol exposure in rats" is preferable to "I am impressed with Dr. Susan Doe's many publications in prestigious journals dealing with rats and alcohol." Mentioning more than one faculty member is useful, as individual faculty members may retire, move, go on sabbatical, or have full labs. Although you may have very defined interests, be careful about seeming narrow or close-minded. Just as you may have changed majors in college, it is possible that your research/training focus may shiftslightly in graduate school.

\section{TIPS}

- Avoid writing a generic paragraph and using it for every program to which you apply. The selection committee easily will identify this strategy. If you can't figure out what is special about the program, then why apply?

- Have plans for your future with defined interests. Recent research suggests that successful versus unsuccessful statements are more likely to emphasize the applicant's identity as a young scientist, rather than primarily focusing on the applicant's past accomplishments (Brown, 2004).

- Have realistic plans for your future. For example, it is unlikely that you will open a private practice in clinical psychology immediately following graduation. You do not want the selection committee to perceive you as naïve and/or unprepared. 
- Read Birchmeier, Shore, and McCormick (2008) and Dirlam (1998) for information about identifying the characteristics of graduate programs and assessing your fit.

\section{Concluding Paragraph: 4-5 sentences}

If you have done your job, the selection committee should have a clear idea of who you are and what you would bring to their program by this point in the paper. Thus, your goal for the last paragraph is to close the paper on a strong note. One option is to return to the original picture that you painted in the opening paragraph. Reference the idea again as a bookend, connecting the imagery at the end of the paper to the imagery that opened the paper. This reminder helps package all of the information in the body of the paper around a central idea of who you are.

This paragraph also affords you the opportunity to express your willingness to meet with the selection committee and/or provide them with additional information. Show enthusiasm about the possibility of being accepted to the program, but don't write as though your acceptance is guaranteed. "I would welcome the opportunity to express my interest in your program in person" is better than "I look forward to being a graduate student in your program" or "I will work very hard in your graduate program." This paragraph is your last chance to make a lasting impression.

\section{TIPS}

- Stay short and focused. The last paragraph is not the place to insert important, new information.

- Seek feedback from professors once your paper is written. Your paper ultimately needs to reflect you; however, you should consider the input from multiple reviewers.

- Revise, revise, and revise. Good writing is a process that takes time. Many students submit the first or second draft of their personal statement; revising beyond that might just give you a competitive edge.

\section{References}

Appleby, D. (2003, Winter). What does your transcript say about you, and what can you do if it says things you don't like? Eye on Psi Chi, 7(2), 21-23.

Appleby, D. C., \& Appleby, K. M. (2007, Spring). How do avoid the kisses of death in the graduate school application process. Eye on Psi Chi, 11(3), 20-21.

Appleby, D., Keenan, J., \& Mauer, B. (1999, Spring). Applicant characteristics valued by graduate programs in psychology. Eye on Psi Chi, 3(3), 39.

Birchmeier, Z., Shore, C., \& McCormick, S. (2008, Summer). Getting in: Finding your fit in a graduate program. Eye on Psi Chi, 12(4), 24-27. 
Brown, R. M. (2004). Self composed: Rhetoric in psychology personal statements. Written Communication, 21(3), 242-260.

Collins, L. H. (2001, Winter). Does research experience make a significant difference in graduate admissions? Eye on Psi Chi, 5(2), 26-28.

Dirlam, D. K. (1998, Fall). Applications that make the schools you want, want you. Eye on Psi Chi, 3(1), 29-30.

Khemlani, S. (2008). Bolstering an application. In A. Kracen \& J. L. Wallace (Eds.) Applying to graduate school in psychology: Advice from successful students and prominent psychologists (pp. 129- 149). Washington, DC: American Psychological Association.

Landrum, R. E. (2002, Winter). Maximizing undergraduate opportunities: The value of research and other experiences. Eye on Psi Chi, 6(2), 15-18.

Norcross, J. C., Kohout, J. L., \& Wicherski, M. (2006, Winter). Graduate admissions in psychology: I. The application process. Eye on Psi Chi, 10(2), 28-29, 42-43.

Osborne, R. E. (1996, Fall). The "personal" side of graduate school personal statements. Eye on Psi Chi, 1(1), 14-15.

Merry Sleigh, PhD, earned her BA in psychology and English from James Madison University (VA). In 1996, she received her PhD in developmental psychology from Virginia Tech, with a specialization in prenatal and infant development. She first served as faculty advisor to Psi Chi at George Mason University (VA), where she received the Regional Faculty Advisor Award in 2003. Dr. Sleigh currently teaches at Winthrop University. She serves as the Psi Chi faculty advisor and as a reviewer for the Psi Chi Journal of Undergraduate Research. Winthrop University Psi Chi chapter was recently honored with a Regional Chapter Award. 